\title{
Empresa, poder e individuo: El neoliberalismo como productor de subjetividad ${ }^{1}$
}

\section{Company, power and individual: Neoliberalism as producer of subjectivity}

Recibido: 03 de diciembre de 2015 - Revisado: 14 de abril de 2016 - Aceptado: 02 de mayo de 2016

José Miguel Segura Gutiérrez ${ }^{2}$

\section{Resumen}

En el artículo se indaga por cómo la empresa produce cierta subjetividad en el individuo, desde la tensión suscitada entre marcos institucionales y prácticas sociales en el contexto neoliberal. Destacando el concepto de empresa como constructo social y aparato de poder, que vía función directiva y toma de decisiones, asegura la configuración de cierto orden social, que a la vez reproduce la lógica de capital -incremento de la productividad y capacidad de consumo-. Esto último, con miras a señalar que en la relación empresa-individuo, no solo es posible un acercamiento económico-administrativo, sino también filosófico y social, frente a las diferentes dinámicas de socialización y procesos de individuación, que estructuran la vida de los individuos al interior del espacio laboral.

\section{Palabras clave}

Organización, persona, relaciones de autoridad, subjetividad.

\begin{abstract}
This article explores how the company produces certain subjectivity in the individual, from the tension between institutional frameworks and social practices in the neoliberal context. The concept of a company is emphasized as a social construct and apparatus of power, which via management function and decision-making, ensures the configuration of a certain social order, which simultaneously reproduces the logic of capital-increment of productivity and consumption capacity-. The latter, with a view to pointing out that in the company-individual relationship, not only an economic-administrative approach, but also a philosophical and social approach is possible, facing the different dynamics of socialization and processes of individuation, which structure the life of individuals inside the work space.
\end{abstract}

\section{Keywords}

Organization, person, authority relationships. subjectivity.
${ }^{1}$ Artículo de reflexión que forma parte de la producción académica asociada a la línea de investigación en "Socialización Política" (2015-2016), de la Maestría en Desarrollo Educativo y Social de la Universidad Pedagógica Nacional, Bogotá, Colombia.

2 Estudiante de maestría en Desarrollo Educativo y Social, Universidad Pedagógica Nacional, Bogotá Colombia. Especialista en Gerencia Social, Corporación Universitaria Minuto de Dios, Bogotá, Colombia. Administrador público, Escuela Superior de Administración Pública, Medellín, Colombia. Docente Universidad Cooperativa de Colombia Villavicencio, Colombia. Correos electrónicos: jose.segurag@campusucc.edu.co; josemielsegura@gmail.com

Para citar este artículo use: Segura, J. (2016). Empresa, poder e individuo: El neoliberalismo como productor de subjetividad. Civilizar Ciencias Sociales y Humanas, 16(31), 113-126. 


\section{Introducción}

El pensamiento administrativo durante el último siglo -taylorismo y fordismo- ha contribuido de manera significativa al crecimiento de la economía mundial, a partir de la adopción de ciertos modelos administrativos, sobre los cuales se definen las formas de producción y comercialización empresarial de bienes y servicios en el mercado, así como las relaciones entre el individuo y la organización.

Reflexionar en torno a las posibilidades de constitución subjetiva que ofrece al individuo la empresa en tanto paradigma socioeconómico moderno, advierte no solo el uso de dispositivos ${ }^{1}$ (reglamentos, organigramas y prácticas de saber especializado), favorables al cumplimiento de los fines organizacionales, sino también, de la producción de un sujeto independiente para proveerse una vida buena, a partir de un individualismo institucionalizado que se gesta desde las dinámicas de mercado, precariedad de los vínculos sociales en tanto factores estructurantes de la experiencia humana en el momento actual.

[...] la aparición de la empresa moderna obedece a una función social clara, relacionada con la necesidad de optimizar el funcionamiento de los mercados, a través de la apropiación, organización y dirección de los recursos necesarios para la producción y prestación de productos y servicios. De hecho, es a partir de ese momento cuando se empieza a configurar en el sistema social un único poder soberano, el poder económico, al que se subordinan todos los demás poderes, dictando normas, estableciendo sus estrategias y valiéndose de la organización como unidad instrumental esencial, cuya influencia atraviesa todo el espectro de la realidad social, comenzando por sus propios individuos (Zarco \& Rodríguez, 2005, p. 187).

Para Melgoza (1999) desde el taylorismo o scientific management se piensa a la subjetividad obrera "como un elemento que puede $-\mathrm{y}$ debe - ser moldeado si se le ataca por dos flancos" (p. 175). Por un lado, desde la reducción del conocimiento del obrero frente a su oficio vía distribución de tareas, y por otro, desde el control al accionar del obrero y su incapacidad para formar colectivos. Situación que contrasta con lo que expresan Zuleta y Daza (1997), en el sentido que:

El sujeto que el capitalismo produce es toda una novedad: sujeto de la urbe, sujeto de la masa, intimidad vehiculada por la imagen que lo privatiza y lo potencializa en su mismidad, a nuestro juicio, el único lugar donde el sujeto se nombra (p. 146).

Desde la unidad dialéctica de los procesos productivos (hombre-organización), la única relación posible es aquella con sustento en un acuerdo de base jurídica, que exige al individuo el cumplimiento de obligaciones y metas, pero desatiende para sí misma, su compromiso por generar visiones compartidas del mundo en el trabajador. De acuerdo con Freire (s.f.) "Los animales no 'admiran' el mundo. Están sumergidos en él. Los hombres, por el contrario, como seres del quehacer, 'emergen' de él y, objetivándolo, pueden conocerlo y transformarlo con su trabajo" (p. 111).

Al hablar de las prácticas y estrategias de poder que pone en marcha la organización empresarial para consolidar su plan de gestión -crecimiento y rentabilidad-, lo que se revela es la adopción de cierta racionalidad estratégica, dirigida a obtener el máximo beneficio, a partir de la aplicación de un poder instrumental conformidad, obediencia y subordinación- a la ejecución de tareas, alcance de metas y selección de los sujetos más aptos para realizarlas. Esto incluso cuando se sabe que:

El individuo no totaliza una sociedad global directamente. Lo hace a través de la mediación de su contexto social inmediato y de los grupos limitados de los cuales forma parte [...] De igual manera, la sociedad totaliza a cada individuo específico a través de las instituciones mediadoras [...] (Ferraroti, 1983/1988, citado por Blanco, 2012, p. 55). 
En ese sentido, el artículo indaga por cómo la empresa logra producir cierta subjetividad en el individuo-trabajador y describe la tensión suscitada entre marcos institucionales y prácticas sociales en la condición neoliberalcapitalista. Al decir de Domingo (1994) "La empresa no es un grupo humano cualquiera. Nos hallamos ante un grupo capaz de generar riqueza, de responder a unas necesidades sociales y de evaluar las dimensiones de su productividad" (p. 101).

Teniendo en cuenta lo anterior, este texto destaca el concepto de empresa como constructo social y aparato de poder, que vía función directiva y proceso de toma de decisiones, busca asegurar la configuración de cierto orden social clave a sus intereses, pero sin desconocer, su vinculación a una lógica capitalista que le conecta con el crecimiento, incremento de la productividad y generación de contenidos de consumo $^{2}$ en la conciencia individual. En la relación empresa-individuo, no solo hay lugar para un acercamiento económico-administrativo -vectores de dirección, velocidad y tiempos-, sino de dinámicas de socialización y procesos de individuación, en que participa el sujeto contemporáneo.

Desde los procesos económicos, la empresa deviene en un espacio para la producción de la subjetividad, ya no solo en materia de disciplina, sino como espacio amplificador de la desterritorialización propia de la interacción entre los modos de control y la globalización del capital, al decir de Martínez (2010).

\section{La empresa: concepto y constructo}

No cabe duda de que la modernidad en tanto forma temporal-histórica favorece la emergencia de una razón instrumental, cuya consolidación se traduce hoy en el diseño y gestión administrativa de organizaciones, cuya incidencia en la configuración del individuo como sujeto social resulta significativa. Tanto porque "los individuos aparecen abandonados a su suerte, en medio de esta gran maquinaria abstracta, donde la única solución parece ser el terapeuta de turno que promete la salvación del alma a cambio de entregar la propia conciencia" (Uribe, 1999, p. 68). Como también, porque la estructuración de la vida y restricción de las posibilidades de elegir por parte del individuo, están dadas en razón a que:

El marco productivo construye subjetividades inmersas en la lógica del mercado y su intercambio, pero a la vez hace emerger eventualidades peligrosas de orden biopolítico: la muerte como fin de las posibilidades productivas, de desempleo o la quiebra, el paro y la huelga. El sujeto también deviene en peligroso: sujeto no productivo, destructor del interés social al no tenerlo en cuenta (delincuencia, antisocial), sujeto no controlado, bandido (Perea, 2005, p. 59).

Cuestión que ilumina el camino para ver cómo los procesos de cambio auspiciados por el proceso globalizador han generado al interior de las sociedades actuales, resignificaciones conceptuales y operacionales de lo que es la empresa en tanto organismo social y aparato de poder. "La empresa, [...] instituye entre los individuos una rivalidad interminable a modo de sana competición, con una motivación excelente que contrapone unos individuos a otros y atraviesa a cada uno de ellos" (Deleuze, 1996, pp. 249-250).

Al analizar cómo un sistema económico basado en el consumo favorece la proliferación de mecanismos de producción de la subjetividad y ampliación de repertorios identitarios, a través del sistema-mundo, lo que revela, es la necesidad de activar un espíritu partícipe y diseñador de estrategias articuladoras entre teoría y praxis, que afincadas en la realidad permitan dar cuenta de las coordenadas histórico-sociales en que se inserta el individuo-trabajador en la empresa:

La cuestión no es [...] saber cómo el individuo se integra a la sociedad por la socialización o se libera por medio de la subjetivación, sino de 
dar cuenta de los procesos históricos y sociales que lo fabrican en función de las diversidades societales (Martucelli, 2007, p. 30).

De acuerdo con Freire (2002) "Solo somos porque estamos siendo. Estar siendo es, entre nosotros, la condición para ser" ( $p$. 19). Razón por la cual, el objeto de analizar la realidad en que uno vive, no sea otro, que el de dar visibilidad a las situaciones y concreciones históricas en que transcurre la vida del individuo.

Al fin y al cabo, mi presencia en el mundo no es la de quien se adopta a él, sino la de quien se inserta en él. Es la posición de quien lucha para no ser tan solo un objeto sino también un sujeto de la historia (Freire, 2002, p. 53).

Los individuos como protagonistas de su propia historia, cuentan con dos recursos importantes para convertirse en sujetos, a saber, la intencionalidad y el lugar social donde se desarrolla su existencia humana y logran generar conciencia -reflexión y acción transformadora-, frente a la realidad que demanda su tiempo histórico.

Tiempo, en el que la capacidad del sujeto para estar en tránsito dentro de la realidad, se hace cada vez más frágil, compleja y desafiante, pero sin restringirle, la posibilidad de interpretar válidamente las condiciones de su propia existencia en el mundo. La "existencia ya no se encuentra separada del sentido" (Vattimo, 1992, p. 27), pero sí transformada temporalmente dentro de una estructura cultural valorativa que otorga significado al devenir del sujeto. Un devenir, alinderado a formas de reproducción económico-capitalistas, que endurecen las condiciones de vida de los individuos, y a su vez, permiten observar cambios en las normas y valores socioeconómicos, como producto de la generación de imágenes de consumo deseables e inevitables para cada una de las diferentes esferas en que transcurre la existencia humana.

Fue la empresa, desde la racionalidad neoliberal del laissez-faire, quien transformó al individuo en un "empresario de sí", que hoy invierte su dinero y esfuerzo para mejorar su empleabilidad y salario. Esto sin descontar su configuración de individuo-trabajador a sujeto-consumidor. La noción de empresario de si a lo que hace referencia es a un agente autoproducido, fuente de sus propios ingresos y comprometido afectivamente con su empresa.

Situación esa, que permite señalar cómo al interior de la empresa, "El tiempo de los unos debe ajustarse al tiempo de los otros de manera que la cantidad máxima de fuerzas pueda ser extraída de cada cual y combinada en un resultado óptimo" (Foucault, 2002, p. 169). Resultado que dependerá inexorablemente del sistema de mando. "Toda actividad del individuo disciplinado debe ser ritmada y sostenida por órdenes terminantes cuya eficacia reposa en la brevedad y la claridad" (p. 170).

Aunque en algunas organizaciones empresariales la figura del jefe como portador de la autoridad ya no es vista según la mirada de un inquisidor e intransigente sujeto, aún no es posible afirmar que este mismo individuo haya renunciado al uso de la norma y por ende, a la sanción que de ella se desprende como mecanismo disciplinante y asegurador de los fines de la empresa y la realización misma del proyecto de vida del trabajador.

Para la disciplina no se trata ni de expiar una culpa ni de reprimir, sino de referir las conductas del individuo a un conjunto comparativo, diferenciar los individuos, medir capacidades, imponer una "medida", trazar la frontera entre lo normal y lo anormal (Castro, 2004, p. 87).

Razón esa, para que la función activa, complementaria y siempre vigilada de las actividades que desarrolla el empleado-trabajador en el proceso de producción y alcance mismo de las metas establecidas por la dirección, encuentre justificación a partir del concepto de empresa, entendido como "la unidad económico-social en la que el capital, el trabajo y la dirección se coordinan para lograr una produc- 
ción que responda a los requerimientos del medio humano en el que la propia empresa actúa" (Guzmán, citado por Munch, 2009, p. 44).

La meta de la actividad empresarial es la satisfacción de necesidades humanas a través de la puesta en marcha de un capital, del que es parte esencial el capital humano -los recursos humanos-, es decir, las capacidades de cuantos cooperan en la empresa. Por tanto, el bien interno de la actividad empresarial consiste en lograr satisfacer esas necesidades $\mathrm{y}$, de forma inseparable, en desarrollar al máximo las capacidades de sus colaboradores, metas ambas que no podrá alcanzar si no es promocionando valores de libertad, igualdad y solidaridad desde el modo especifico en que la empresa puede y debe hacerlo (cursivas del autor, Cortina, 1994, p. 43).

Es decir, mediante la visibilidad de las condiciones de posibilidad que como organización dotada de poder tiene, para potencializar las habilidades y desarrollar la libertad en sus trabajadores, de acuerdo con las particularidades que cada uno de estos presenta en la escena laboralorganizacional. Finalmente, "la existencia de la empresa se encuentra en la coordinación de elementos humanos y materiales, y de las funciones técnicas que completas y coordinadas logran la producción de bienes y servicios para el mercado" (Reyes, 1994, p. 159). Además de consolidar un mundo de trabajo caracterizado por transformaciones subjetivas, que tensionan las aptitudes $\mathrm{y}$ competencias que se requieren en el proceso productivo frente a su factor humano.

\section{Empresa, neoliberalismo y poder: la aparición del sujeto}

Si en otrora lo más importante dentro de las relaciones laborales era la fuerza de trabajo o capacidad concreta de producción que ofrecía el individuo-trabajador a la empresa, hoy este modelo administrativo quizá más cercano al pensamiento de Marx, pero no de Elton Mayo, ha ido cambiando por uno que ahora se ocupa de lo humano-personal que habita en el homo economicus del intercambio comercial que estableció el neoliberalismo en tanto sistema económico.

Desde hace ya más de cincuenta años, esta forma de racionalidad complejiza la realidad de los individuos y produce una desterritorialización de sus instancias simbólicas y culturales, en detrimento de la constitución subjetiva de los sujetos, pero también de la resistencia necesaria a desarrollar por parte de las poblaciones, ante ciertas prácticas de gobierno biopolítico, que buscan con premura imponer decisiones gubernamentales de tipo económico, sin vislumbrar sus consecuencias más inmediatas en el contexto y sus actores (desempleo, hambre, malestar subjetivo y violencia). Tanto así, que desde la perspectiva de Castro-Gómez (2010):

[...] lo que se considera sustancialmente personal no es otra cosa que un cierto tipo de sensación que se efectúa a través de un particular poder que ya no opera normalizando la subjetividad mediante el confinamiento de los individuos, sino modulando sus deseos en espacios abiertos (p. 212).

Por eso, que al considerar la empresa como un espacio relacional-operacional del mercado -vía clientes y trabajadores-, no solo se resalte su condición física como lugar, sino también, de ámbito dinamizador de aquellos procesos mediante los cuales se produce el sujeto dada su experiencia vital, y entendida aquí a modo de una práctica social que revela sistemas de acción estructurados socialmente. La práctica social hace visible:

[...] por una parte, las condiciones sociales, históricas y materiales en las que ella se inscribe, y por otra, su modo de apropiación por el individuo o grupo respectivo. Para que una práctica social, aún impuesta, se mantenga, es necesario todavía que pueda, con el tiempo, ser apropiada, es decir integrada al sistema de valores, creencias y normas (Abric, 2001, p. 213). 
Esto en el entendido, que:

[...] las prácticas sociales, en tanto acontecimientos materiales, constituyen la realidad social, que adquirirá diferentes expresiones según el entramado de aquellas. Las prácticas sociales pueden pertenecer a tres esferas: parental, económica y política. La primera garantiza la generación, mantenimiento y formación de hombres y mujeres, la segunda la producción de las condiciones materiales para la vida social y, la tercera, la creación de categorías sociales que trascienden la condición sexual (Castro et al., 1996, p. 35).

Como insistió Foucault, explicando la génesis del neoliberalismo, la propia población pasa a ser objeto del saber y el poder, en razón a que las prácticas sociales refieren a la actividad que ejecuta el ser humano sobre su entorno más inmediato y de manera intencional, tanto así, que:

Podríamos decir que la humanización de los empleos -en el sentido similar al que dio Foucault a la humanización de la penalidad mediante la prisión y cuya otra cara consiste en el desarrollo de las tecnologías disciplinarias- entraña una normalización que coloniza y produce subjetividades articulando afectos, deseos, prioridades personales. Sin embargo, por más que se exalten como personales, esta demanda podría concebirse como el inicio de un proceso de (auto)reificación y desingularización (Amigto \& Martínez, 2013, p. 111).

La autorreificación como ejemplo de las prácticas de sí que efectúa un individuo sobre sí mismo, contiene elementos del innatismo natural y de los aprendizajes adquiridos a lo largo de su experiencia vital, que deben ajustarse a criterios de racionalidad instrumental exigidos por los procesos productivos. Las prácticas de sí, en amplio sentido, son un conjunto de técnicas que permite a los individuos efectuar un número de operaciones en sus propios cuerpos, pensamientos y conductas, que dado el caso podrían poner en riesgo a la empresa, por lo cual se justifica la aplicación de poder.
En el incremento de la productividad se ponen en juego no solo factores de costo sino culturas, subjetividades e interacciones en los lugares de trabajo, que pueden ir a favor o en contra de la productividad más allá de la contabilidad de la empresa (De la Garza, 2002, p. 12).

$\mathrm{Si}$ se entiende que el sujeto y su subjetividad son derivaciones de la capacidad de agencia que poseen los individuos de acuerdo con condiciones y prácticas históricas extremadamente diversas, pero colaborativas frente a los modos en que nos constituimos a nosotros mismos como producto de la tensión de fuerzas y relaciones que buscan transformar al animal humano en sujeto, cabe pensar que:

Ninguna otra técnica de conducción de la vida liga al individuo tan firmemente a la realidad como la insistencia en el trabajo, que al menos lo inserta en forma segura en un fragmento de la realidad, a saber, la comunidad humana (Freud, 1998, p. 80).

Para Foucault:

Hay dos significados de la palabra sujeto: sometido a través del control y la dependencia, y sujeto atado a su propia identidad por la conciencia o el conocimiento de sí mismo, ambos significados sugieren una forma de poder que subyuga y somete (Foucault, 1988, p. 7).

El poder es para Foucault, la vía que el ser humano encuentra para construirse como sujeto y controlarse a sí mismo y a los demás. De ahí, que el neoliberalismo no solo haya actuado como una ideología a favor del mercado y en desmedro del Estado de bienestar, sino también como "constructor" de nuevas subjetividades, desde el individualismo y la lógica empresarial misma. Es decir, desde situaciones que al ser ubicadas dentro de la lógica del capitalismo contemporáneo con sus flujos financieros y experiencias de consumo gestadas en el mercado, implican para la subjetividad no solo su fragmentación, sino "un campo de alienaciones nuevas para los sujetos, debido a la fuerza aplastante del mundo de las mercancías, 
la circulación de saberes y la influencia de los flujos de información instalados en forma potencial" (Niño, 2008, p. 43). Ahora, el sujeto neoliberal se unifica como empresario de sí y vive en una continua relación con los excesos, el rendimiento y la competencia.

El sujeto se define por un movimiento y como un movimiento, movimiento de desarrollarse a sí mismo. Lo que se desarrolla es el sujeto. Ese es el único contenido que se le puede dar a la idea de subjetividad: la mediación, la trascendencia. Pero observamos que el movimiento de desarrollarse a sí mismo o de llegar a ser otro es doble: el sujeto se supera, el sujeto se reflexiona (Deleuze, 1996, p. 91).

En ese orden de ideas, afirmar que la subjetividad es producto de la socialización a la que no escapa ningún individuo, y que ella remite al adentro del pensamiento de cada sujeto -a la forma en que concibe y participa del mundo (realidad) a través de su mentecuerpo-, sea el pretexto para acercarse a la comprensión de la producción subjetiva en la empresa, con sus técnicas de gestión, dispositivos de evaluación, en tanto puntos nodales de la racionalidad neoliberal. Si de algo no hay duda es que el sujeto neoliberal vive en los márgenes de su libertad, en el goce y la competencia por constituirse en el actor de su propia vida, y crear desde allí un hábitat, que supere lo precario, líquido y desconocido que para él mismo constituye el tiempo actual.

Conceptualmente, la subjetividad en el trabajo implicaría entender la forma en cómo los sujetos interactúan al interior de la empresa y no solo eso, en un nivel más profundo, traerá consigo la necesidad de entender la influencia que tienen los sistemas de organización racional del trabajo en el psiquismo del trabajador (Carrillo, Salinas, \& Martínez, 2009, p. 27).

Si se atiende a que el fin último del neoliberalismo es la producción de un sujeto nuevo, un sujeto homogeneizado a causa de la lógica empresarial, competitiva y tecnocomunicacio- nal, que reduce su miedo a la soledad y favorece la proximidad social, cabe preguntar si en dicha relación existe la posibilidad de constituir referentes simbólicos que le permitan al individuo elaborar una política de resistencia a los dispositivos que amarran su cuerpo y subjetividad.

Como se ha visto, el mundo del trabajo trae consigo retos para la subjetividad, en el sentido que inserta a sus portadores en procesos rígidos y carentes de verdad frente a sí mismos y los demás ${ }^{3}$. Olvidando que la subjetividad en tanto acontecimiento se ubica en un entramado de relaciones sociales, políticas y económicas, que hacen del sujeto un agente sociohistórico, visible y responsable de sus acciones-participaciones en el mundo ${ }^{4}$.

De ahí, que interrogarse por el conocimiento que tenemos de sí mismos, sea la clave para avanzar en la configuración de la subjetividad, como residente del espacio corporal y mental de un individuo, cuya "particularidad" se halla animada por la posible respuesta a la pregunta ¿quién eres? Interrogante que se vincula a la discusión filosófica de tradición socrática, pero a su vez, asociado a las prácticas de autocontemplación y representaciones sociales que el sujeto desarrolla frente a los espacios en los cuales ha transcurrido su vida. ¿Qué piensas? ¿Qué sientes? ¿Qué te gustaría hacer? ¿Ese "algo a hacer" te gustaría que perdurara? Son algunas de las incógnitas que asaltan la mente de muchos trabajadores que buscan establecer la verdadera esencia de su ser, aunque para el poeta latino Ovidio (2004) "hay en los corazones tantos modos/de ser, como expresiones en el rostro" (p. 429).

Afirmación que busca considerar cómo los cambios ocurridos en la organización del trabajo y el modelo de relaciones laborales adoptado por la empresa, tienen unos efectos que se observan en la subjetividad de sus empleados y que se asocian al desarrollo de tareas y aprendizajes requeridos para su ejecución, más que con la dimensión emocional, en tanto factor nuclear del 
potencial ejecutivo que tienen los sujetos. Pues al hablar del mundo del trabajo se alude no solo a un espacio donde se lleva a cabo una actividad, sino también, donde se posibilita la transformación de la naturaleza del hombre, a partir del mejoramiento de sus destrezas y adquisición de habilidades para insertarse en lo social.

Es decir, en ámbitos donde el ejercicio de la autonomía y expresión motivacional, permiten potenciar la constitución subjetiva de cada individuo y garantizar así la definición de su voluntad de poder. Incluso cuando el neoliberalismo parece corporeizarse en una máquina destructora de reglas y lazos sociales, que configura a su vez, una nueva organización de las relaciones personales y socioempresariales.

Por último, "los procesos de producción de subjetividad se entienden como fuerzas transformadoras y se constituyen en procesos de subjetivación, pero que se autodeterminan o autoorganizan de manera más autónoma [...]" (Niño, 2008, p. 120).

\section{Poder y modos de subjetivación en la empresa}

Llegamos al mundo en el mejor de los casos como producto de la decisión compartida de una pareja, por conformar una familia y ajustarse así, al modelo sociocultural establecido. Sin embargo, como nuevos miembros de dicha unidad, nos hallamos expuestos a la continua aplicación de protocolos que buscan garantizar la integralidad y control de sí mismos según ciertos contextos y situaciones.

Cuestión que deja ver cómo el poder, parafraseando a Foucault (Deleuze, 1987), más que poseerse se ejerce, de acuerdo con el agregado de posiciones estratégicas en que se ubica el individuo dentro de un entramado heterogéneo de relaciones (p. 51).

Al interrogarnos por la forma en que las organizaciones ejecutan su poder de mando sobre los empleados, sea necesario aclarar que dicha aplicación de poder, requiere al menos de dos elementos claves para su configuración, a saber: "el otro (aquel sobre el cual es ejercido el poder) y un campo entero de respuestas, reacciones, resultados y posibles invenciones que pueden atribuirse" (Foucault, 2001, p. 15). Siguiendo a Castro-Gómez (2009) la subjetivación no se efectúa de manera arbitraria con respecto a las aspiraciones de los sujetos; por el contrario, es el sujeto mismo quien elabora $\mathrm{y}$ vive todo un imaginario de progreso. Que dada la coyuntura actual, define la constitución del sujeto, desde la afirmación de un modo de subjetivación $^{5}$ en el cual la sobrevivencia se da a partir de la dupla tiempo-capital, en tanto factores constitutivos del condicionamiento social y automodelamiento ${ }^{6}$.

Pues si bien es cierto, aunque lo que interesa en el estudio del poder según Foucault son los deseos, prácticas y saberes que este produce, no se puede desconocer, que ese mismo poder ha invadido nuestra vida, a tal punto de ser hoy un elemento fundamental para la implantación de la disciplina capitalista, a través de la inserción controlada de los cuerpos en el aparato de producción y mediante el ajuste de las dinámicas poblacionales a los procesos económicos.

Si existe un régimen de subjetivación particular-el empresario de sí- en el presente, este se debe a la presencia problematizadora no solo de un conjunto de reformas estructurales económico-políticas, sinotambién de innovación ética, cultural, que desde la denominación de neoliberalismo, ha hecho realidad la existencia de un nuevo sujeto -empresario de sí-, cuya característica principal es ser administrador y controlador de sus prácticas, según una lógica de optimización de sí mismo.

"El poder en tanto relación de fuerzas, tiene como función incitar, suscitar, combinar [...] más que reprimir 'produce realidad' y más que ideologizar, más que abstraer u ocultar, produce 
verdad" (Deleuze, 1987, p. 54) Con respecto al ejercicio del poder, hay que decir que este requiere de cierta proyección y relacionamiento con otras dimensiones de realización del individuo, las cuales no están guiadas por su carácter visible y a controlar (actos de un sujeto o los datos obtenidos vía sense data), sino por el conjunto de acciones y reacciones que sale a luz y se problematiza para garantizar el desarrollo de la acción productiva, desde la obediencia como singularidad manifiesta del poder en la empresa.

En el campo de las organizaciones, el poder se comprende a partir de las relaciones tanto verticales (relaciones ascendentes y relaciones descendentes), relaciones entre jefes y subordinados, como horizontales, agentes de una misma área, dueños, socios, que en el interior de las organizaciones se ejercen (Álvarez, 2011, p. 150).

El poder que ejerce la empresa y aceptan sus empleados, se haya mediado por un criterio de funcionalidad propio de los sistemas sociales, cuya orientación está dada hacia la homogeneización de sus órganos, como producto de la fuerte estructuración administrativa y capacidad de absorción, de aquellos poderes individualizados y carentes de legitimidad, que compiten por un lugar visible al interior de la organización, pero también como recurso estratégico en la interacción de los trabajadores.

Situación susceptible de ser comprobada por la internalización de pautas surgidas desde las estructuras económicas, y que llevan a que el éxito o fracaso en la consolidación de los respectivos proyectos de vida de los empleados-trabajadores, esté mediado por la optimización en el uso del tiempo, con respecto a la generación de capital, definición estética y potenciación de todas las capacidades hacia la consolidación de una imagen-producto para el mercado.

De acuerdo con Yela e Hidalgo (2010) "El ejercicio de poder radica, entonces, explica Foucault, en conducir o guiar la posibilidad de conducta y disponer la posible consecuencia" (p. 61). Para lo cual, las nociones de "disciplina" y "vigilancia" resultan necesarias a la hora de explicar el ejercicio del poder en la interacción cotidiana.

La existencia de la disciplina permite fabricar cuerpos sometidos y ejercitados, cuerpos dóciles; aumenta las fuerzas del cuerpo (en términos económicos de utilidad) y disminuye esas mismas fuerzas (en términos políticos de obediencia), en tanto que inspecciona de forma minuciosa el detalle, las cosas pequeñas, detalla el cuerpo del hombre para su control y utilización [...] (Yela \& Hidalgo, 2010, p. 62).

Mientras que por su parte la vigilancia con su carácter anónimo y fuertes nexos con lo jerárquico, posibilita el control de las tareas.

Como explica Foucault, en los talleres y fábricas la vigilancia constituye un control intenso y continuo que acompaña en su totalidad el proceso de trabajo y forma parte integrante del proceso de producción. No se acoge solamente a la producción, sino que tiene en cuenta aspectos como las habilidades de los hombres, sus actividades, su rapidez en la ejecución del trabajo y su conducta (p. 63).

El establecimiento del poder de control sobre los individuos vinculados a la organización empresarial, lo que pretende es transformar al individuo en sujeto. En otras palabras, en un producto de los acontecimientos y reflexiones en que este mismo participa en razón de su ser, saber y hacer, dentro de la dialéctica histórica.

La subjetividad producto de los dispositivos de poder, de sus técnicas disciplinarias y de vigilancia, posibilita una organización del trabajo que no altera la asimétrica distribución de poder ni el orden establecido entre los gestores de la producción y los trabajadores (p. 69).

Pero sí revela, cómo:

La generalización de la subjetividad empresarial que se expresa en la voluntad de transformar a 
cada individuo en empresa individual lleva a paradojas. La autonomía, la activación y el compromiso subjetivo que se le pide al individuo constituyen nuevas normas de empleabilidad [...] por otro lado, la incitación a la acción, a la toma de iniciativa y al riesgo individual terminan en la depresión, enfermedad del siglo próximo, expresión del rechazo a asumir una homogeneización y un empobrecimiento de la existencia traída por el éxito individual del modelo empresarial (Lazzarato, 2010).

El proceso de socialización que realiza la empresa en tanto dispositivo, a lo que se dirige es a generar un conjunto de actitudes, creencias, conocimientos y modelos de comportamiento que influya positivamente en el sistema productivo y la configuración identitaria ya no del individuo-trabajador, sino del sujeto articulado a un discurso y régimen de verdad al cual le aporta sus capacidades individuales para lograr la consecución de fines propios.

Esto en razón a que la subjetividad entendida aquí como proceso, no solo devela un "conjunto de prácticas que hacen posible al ser humano en tanto sujeto reflexivo, es decir, sujeto de conocimiento de sí mismo, y sujeto que se gobierna a sí mismo" (Gil, 2004, p. 17) sino que a su vez, muestra cómo la subjetivación en tanto resultado de dicho proceso, depende de la interacción de aquellos factores presentes en un contexto sociohistórico, que leído desde el trabajo como dispositivo de subjetivación, deja ver la forma en que los empleados-trabajadores se relacionan con las reglas de la empresa $\mathrm{y}$ estructuran una racionalidad y manera de actuar (obedecer o transgredir) no solo válida en la escena laboral, sino en las conexiones que esta tiene con otras esferas de la vida social. El proyecto civilizatorio neoliberal, lo que ha producido es una modificación de los comportamientos sociales, cuya lectura ha de hacerse en clave de competencia. De acuerdo con Deleuze (1987), Foucault:

No hace una historia de las instituciones, sino de las condiciones bajo las cuales estas inte- gran relaciones diferenciadas de fuerzas, en el horizonte de un campo social. No hace una historia de la vida privada, sino de las condiciones bajo las cuales la relación consigo mismo constituye una vida privada. No hace una historia de los sujetos, sino de los procesos de subjetivación, bajo los plegamientos que se efectúan tanto en un campo ontológico como social (p. 151).

En suma, las condiciones de saber-poder que establece la empresa a sus trabajadores, se asocian a categorías políticas, económicas y culturales que no solo afectan la formación de nuevas subjetividades, sino también, la existencia y posterior desarrollo de tales organizaciones. Lo anterior, en el sentido que los discursos que estructuran y dan forma a las mismas, activan rizomas que podrían llegar a tensionar las relaciones entre la empresa y sus empleados, dada la solicitud por ejemplo de implementación de manuales de gestión, aplicación de decisiones de carácter administrativo, que no solo buscan modificar las acciones individuales y grupales de los trabajadores, sino también de las familias de estos últimos, en tanto comunidad moral extensa, receptora de informaciones y promotora del mantenimiento del orden establecido.

Pues ahora, el individuo transformado en sujeto, potencia y busca sentido a sus actuaciones pero desde una articulación entre lo uno y lo múltiple, que trae la precarización del trabajo, el incremento del desempleo y la noción de una igualdad acorde con sus capacidades.

\section{Conclusión}

A lo largo de estas páginas intenté señalar cómo la experiencia de trabajo vivida por el individuo en la empresa, visibiliza un complejo entramado de situaciones que no necesariamente pasan por la intermediación sensitiva -ser visto o escuchado-, sino por un juego de relaciones de poder que se produce y reproduce para codificar al sujeto. Tanto desde el ofrecimiento de "bienes de consumo" y "objetos de uso", 
que se estabilizan en el mercado y generan dependencia en los consumidores, como a través de los cambios que la producción misma impulsa en quienes trabajan para producir tales objetos.

La empresa como dispositivo de socialización, no solo cumple con su función económico-comercial, también favorece la fabricación identitaria del individuo y organiza las relaciones sociales - determinar y regular las conductas- de aquellos que participan al interior de dicho espacio organizacional. Por lo cual, preguntar cómo los sujetos perciben la dominación y valoran la utilidad de su ocupación como empleados, muestra la forma en que estos gestan relaciones consigo mismos y con otros que se resisten a los poderes hegemónicos que como el neoliberalismo promociona la empresa.

Desde el proyecto neoliberal los "pobres trabajadores" se constituyen en objeto de intervención gubernamental y de las disciplinas $p s i$, pero se olvida de que ellos pueden ayudar desde sus relatos libres y espontáneos a reflexionar sobre las propias expectativas y liberación de secretos, que se guardan al interior del escenario laboral y que son un riesgo para la comunión y posibilidad de generar conocimiento de sí en los trabajadores, dadas las actuales coordenadas de competencia y homogeneización que esboza la empresa, a través de sus diferentes prácticas, estrategias, líneas de mando y relaciones con el entorno.

Circunstancia que implica una reorientación con respecto al modo como se viene comprendiendo la experiencia personal del trabajo, como función estructurante de la sociedad, pero también de la forma de ser y estar en el mundo. El homo economicus es la subjetividad resultante de la producción biopolítica neoliberal en la sociedad actual.

En últimas, las condiciones de producción de la subjetividad humana en un contexto sociohistórico atravesado por el modelo neoliberal del mercado, llevan a que la subjetividad contemporánea para poder salir de la masificación producida por los medios de comunicación y el repliegue sobre sí misma, tenga que reapropiarse de lo individual y colectivo que tiene la producción subjetiva, en tanto horizonte transformador de las condiciones sociales de la realidad actual.

\section{Notas}

1 Según Jorge Martínez (2013): “El dispositivo puede ser concebido como un medio por el cual se organizan y se sancionan los sujetos, con una correspondencia presente entre el saber y el poder, que se hace visible en las acciones de los sujetos y refleja la constitución del cuerpo en la creación de condiciones de subjetividad" (p. 82). Tal organización, posiciona al sujeto en un espacio y tiempo determinados.

${ }^{2}$ Aquí me refiero a la función aglutinadora que cumple la publicidad con respecto a la visibilidad-existencia de marcas y productos en el mercado, y cuya producción por parte de las empresas posibilita la generación de procesos de identidad y membresía social por parte de quienes las consumen. Esto sin ignorar que la publicidad misma posee una voz indiscriminada, pues puede focalizarse en un grupo, pero sus mensajes están disponibles para todos.

${ }^{3}$ Como varón, las personas esperan muchas cosas de ti. Constituir una familia, adquirir un carro, tener una casa y ser exitoso. Situaciones todas, vinculadas al género y la sexualidad. Sin embargo, para alguien profesional y autorreconocido como homosexual, cumplir con tales expectativas no es fácil. Pues en el centro de tales requerimientos está el tema del trabajo y su posterior compensación con el salario como sustento. Por tal razón, si yo declarara públicamente mi orientación sexual o saliera del clóset, la vida se me complicaría. Primero, porque 
tendría que salir de mi casa materna -donde la verdad vivo bien-; segundo, porque en el trabajo -soy docente universitario- el ser gay me ha convertido en blanco de algunos comentarios y actitudes discriminatorias, que se acrecientan en virtud al interés por estudiar y publicar documentos que tratan de las sexualidades ilegítimas. Pues desde siempre he considerado que mi realización como persona y profesional, se vincula con lo académico, con convertirme en un investigador social. No obstante, esa labor de indagación-reflexión-divulgación, reconfirma mi condición de llanero solitario, lo cual es muy triste, pues lo relaciono con un campo minado, que exige total sigilo si se quiere avanzar en él. Aquí, no hay una amplia sonrisa de satisfacción, similar a la del gato de Cheshire presente a lo largo del recorrido. Por el contrario, lo que existe es una imperceptible posición de resistencia a las técnicas de normalización que se dan en la universidad como centro de saber/ poder (Nota del autor).

${ }^{4}$ Particularmente, para Foucault lo económico funciona en el neoliberalismo como una grilla de inteligibilidad que extiende la forma empresa por la trama social, impregnando con su lógica a todo tipo de proceso social y cultural, inclusive aquellos procesos que históricamente habían sido interpretados como no económicos (Foucault, 2007, pp. 277, 280).

${ }^{5}$ Para Deleuze (1987) "la subjetivación nos es mostrada entonces como un pliegue, como la forma resultante de una fuerza que se afecta a sí misma, mediante ella, ese afuera se constituye en un adentro coextensivo que nada tiene que ver con la interioridad" (p.18).

${ }^{6}$ En cuanto a mí, he buscado la libertad más que el poder. Sin embargo, su encuentro ha sido efímero y costoso. Pues la vida necesita no solo de buenas intenciones, sino de decisiones que la hagan vivible de forma real y no fantástica. Es decir, según una perfecta armonía entre prácticas de sometimiento y estrategias de resistencia personal (Nota del autor).

\section{Referencias}

Abric, J. (2001). Prácticas sociales y representaciones sociales. México: Ediciones Coyoacàn.

Álvarez, Y. (2011). El poder y las relaciones de poder en las organizaciones. Algunas aproximaciones teóricas desde las perspectivas de Michael Foucault, Pierre Bourdieu y Max Weber. Gestión y Sociedad, 4(1), 145-161. Recuperado de http:// revistas.lasalle.edu.co/index.php/gs/article/view/303/237

Amigot, P., \& Martínez, L. (2013). Gubernamentalidad neoliberal, subjetividad y transformación de la universidad. La evaluación del profesorado como técnica de normalización. Athenea Digital, 13(1), 99-120. Recuperado de http://psicologiasocial.uab.es/athenea/index.php/atheneaDigital/article/view/1046- Amigot

Blanco, M. (2012). Autoetnografía: Una forma narrativa de generación de conocimientos. Revista Andamios, 9(19), 49-74. Recuperado de http://www.redalyc.org/ pdf/628/62824428004.pdf

Carrillo, M., Salinas, R., \& Martínez, J. (2009). Efectos subjetivos-sociales dentro de las nuevas formas de organización del trabajo (NFOT). Ciencia@UAQ, 2(2), 25-35. Recuperado de http://www.uaq. mx/investigacion/revista_ciencia@uaq/ ArchivosPDF/v2-n2/Efectos.pdf

Castro, E. (2004). El vocabulario de Michael Foucault. Buenos Aires: Editorial Prometeo.

Castro-Gómez. S. (2009). Tejidos oníricos: movilidad, capitalismo y biopolítica en Bogotá (1910-1930). Bogotá: Universidad Javeriana; Instituto Pensar. 
Castro-Gómez, S. (2010). Historia de la gubernamentalidad. Razón de Estado, liberalismo y neoliberalismo en Michel Foucault: Bogotá: Siglo del Hombre.

Castro, P., Chapman, R., Gili, S., Lull, V., Micò, R., Rihuete, C., Risch, R., \& Sanahuja, M. (1996). Teoría de las prácticas sociales. Conplutum Extra, 6(2), 35-48.

Cortina, A. (Ed) (1994). La ética empresarial en el contexto de una ética cívica. En, Ética de la empresa. Claves para una nueva cultura empresarial (pp. 35-50). Madrid, España: Editorial Trotta.

Deleuze, G. (1987). Foucault. Buenos Aires: Paidós estudio.

Deleuze, G. (1996). Conversaciones. Valencia: Pretextos.

De la Garza, E. (2002). Los dilemas de los nuevos estudios laborales en América Latina. Primera Reunión Subregional de la Asociación Latinoamericana de Estudios del Trabajo (pp. 1-32). Cochabamba, Bolivia. Recuperado de: http://sgpwe.izt.uam.mx/ pages/egt/congresos/bolivia.pdf

Domingo, A. (1994). Ética de la dirección. En A. Cortina (Ed.), Ética de la empresa. Claves para una nueva cultura empresarial (pp. 95-121). Madrid, España: Editorial Trotta.

Foucault, M. (1998). El sujeto y el poder. Revista Mexicana de Sociología, 50(3). 3-20. Recuperado de http://www.jstor. org/stable/3540551

Foucault, M. (2001). El sujeto y el poder. Santiago de Chile: Universidad ARCIS. Recuperado de http://www.slideshare. net/mahummuhu/michael-foucault-elsujeto-y-el-poder
Foucault, M. (2002). Vigilar y castigar. Buenos Aires: Siglo XXI Editores.

Foucault, M. (2007). El Nacimiento de la biopolítica. Buenos Aires: Fondo de Cultura Económica.

Freire, P. (s.f). Pedagogía del oprimido. Bogotá: Editorial América Latina. Recuperado de http://www.servicioskoinonia.org/biblioteca/general/FreirePedagogiadelOprimido.pdf

Freire, P. (2002). Pedagogía De La Autonomía. Buenos Aires: Siglo XXI.

Freud, S. (1988). El malestar en la cultura. Buenos Aires: Amorrortu editores.

Gil, E. (2004). Ultraindividualismo y simulacro en el nuevo orden mundial: reflexiones sobre la sujeción y la subjetividad (Tesis doctoral). Universidad Autónoma de Barcelona, Barcelona.

Lazzarato, M. (Noviembre, 2010). Conferencia internacional: capitalismo y producción de subjetividad. II Congreso Internacional de Investigación y Práctica Profesional en Psicología, Universidad de Buenos Aires, Buenos Aires, Argentina. Recuperado de http://www.youtube.com/ watch? $\mathrm{v}=5 \mathrm{JNQ} 2 \mathrm{pzOcnY}$

Martínez, J. (2010). La universidad productora de productores: entre biopolitica y subjetividad. Bogotá: Universidad de la Salle.

Martínez, J (2013). El dispositivo: una grilla de análisis en la visibilización de las subjetividades. Revista Tabula Rasa, 19, 79-99. Recuperado de http://www.revistatabularasa.org/numero-19/04martinez.pdf

Martuccelli, D. (2007). Cambio de rumbo. La sociedad a escala del individuo. Santiago de Chile: LOM. 
Melgoza, J. (1999). Tras la huella de la subjetividad obrera. Algunas reflexiones desde la sociología del trabajo. Sociológica, 5(14), 171-187. Recuperado de http://www.revistasociologica.com.mx/pdf/1411.pdf

Munch, L (2009). Fundamentos de Administración. México: Trillas.

Niño, R. (2008). Cognición y subjetividades politicas: perspectivas estéticas para la ciudadanía global. Bogotá: Editorial Pontifica Universidad Javeriana.

Ovidio, P. (2004). Amores. Arte de amar. Madrid: Ediciones Cátedra.

Perea, A. (2005). Estética de la existencia. Las prácticas de sí como ejercicio de libertad. Poder y resistencia en Michel Foucault. Bogotá: Autor.

Reyes, A. (1994). Administración moderna. México: Limusa-Noriega editores.

Uribe, A. (1999). Modernidad, ética y empresa. Revista Ideas y Valores, 48(111), 6177. Recuperado de http://www.revistas. unal.edu.co/index.php/idval/article/view/ $8834 / 9478$

Vattimo, G. (Ed.) (1992). Nietzsche y el más allá del sujeto. En, Más allá del sujeto Nietzsche, Heidegger y la hermenéutica (2a ed., pp. 25-45). Barcelona: Paidós.

Yela, J., \& Hidalgo, C. (2010). El poder en Foucault: bases analíticas para el estudio de las organizaciones. Cuadernos de Administración, 26(44), 57-70. Recuperado de http://cuadernosdeadministracion.univalle.edu.co/index.php/cuadernosadmin/ article/view/641/2555

Zarco, V., \& Rodríguez, A. (2005). Ética y responsabilidad social en las organizaciones actuales. Revista Internacional de Ciencias Sociales y Humanidades, SOCIOTAM, 15(2), 185-203. Recuperado de http://www.redalyc.org/articulo. oa? $\mathrm{id}=65415211$

Zuleta, M., \& Daza, G. (1997). Maquinaciones sutiles de la violencia. Bogotá: Universidad Central-DIUC; Siglo del Hombre. 